\title{
Living in Second Life and Learning a Second Language: A Study on English Learning for Chinese Residents in Second Life
}

\author{
Dan Wu \\ School of International Programs/Humboldt College, Xi’an International Studies University, Xi’an, China \\ Email: wudan@xisu.edu.cn
}

Received May 28 $8^{\text {th }}, 2012$; revised June $30^{\text {th }}$, 2012; accepted July $10^{\text {th }}, 2012$

\begin{abstract}
This paper examines Chinese residents' experience in learning English in the 3-D virtual world of Second Life (SL). With an introduction to the current English as a Second Language (ESL) education in China, ESL students' demand for practice, I analyzed an online BBS created and maintained by Chinese SL residents and conducted interviews in SL to argue that there is an urgent need among Chinese ESL learners to practice their English with native English speakers and SL can function as a platform to allow Chinese ESL learners practice with residents from all over the world with help and support provided by their online learning communities such as BBS or SL friends groups.
\end{abstract}

Keywords: ESL; Second Life; E-Learning; Virtual World

Internet has been playing a complex role in human life since its expansion to popular use in early 1990. Its impacts on our life have reached almost every aspect. It also makes the online 3-D Virtual worlds possible and popular. This raises questions to educators and researchers on how the virtual worlds can be utilized as tools to enhance students' learning and meet their needs in this ever changing world.

This paper probes into the English learning experience of Chinese residents in Second Life by analyzing an online BBS created and maintained by some of the Chinese residents and reporting avatar interviews I conducted in SL in order to find out how this virtual world has helped them in learning English as a second language. Recommendations on using SL for ESL professionals are also included in this paper.

\section{Introduction}

"Second Life ${ }^{\circledR}$ is a 3-D virtual world created by its Residents. Since opening to the public in 2003, it has grown explosively and today is inhabited by millions of Residents from around the globe. (What is Second Life, 2008).” According to the economic statistics released by Linden Lab, the company that launched Second Life, by November 2008, the total residents in this virtual world has reached 16 million. Using Second Life (SL) as an educational tool has been studied by researchers in new media literacy, education, communication studies and library studies (Atkinson, 2008; Diehl \& Prins, 2008; DeWinter \& Vie, 2008; Jarmon, Trahagan, \& Mayrath, 2008). Second language education on English is also conducted in SL in the form of either free classes or paid classes (Diehl \& Prins, 2008). English is the official and dominant language in this virtual world, although it is possible for residents to choose other languages to us in chatting or even localize their SL interface by applying language packages.

However, limited previous research has been found on English speaking Chinese residents in SL and their experience in learning English as the second language and improv- ing their proficiency. Unlike massively multiplayer online games (MMOG) or massively multiplayer online role-playing games (MMORPG) such as World of Warcraft, which gained much popularity in China with its release of the Chinese version , Second Life has been only discovered and enjoyed by a limited number of its Chinese residents. There are many reasons that result in this difference, but English as the working language might have contributed much to it. The massive number of players which means thousands of players simultaneously experience the world in a shared space provided Chinese residents opportunities to practice their English with English speakers from all over the world. In this study, an online BBS named "Chinese Second Life League" will be analyzed with an emphasis on the participants' English learning experience in SL to see how the community may help English learners in improving their English proficiency and further explore their "second lives" in this unique virtual environment.

The participants in this BBS are all Chinese who registered as Second Life residents, and they share their SL virtual environment experience in the BBS community. The working language of this BBS is Chinese, and much of their discussion content is in Chinese, but a quite big part of the discussion content is on learning English and communicating with English speakers (either native or non-native) in SL. After analyzing the BBS content, I will then report the avatar interviews I conducted in SL to provide some first-hand research on how these Chinese SL residents perceive their English learning experience in this virtual world. Then comparison and connection between the BBS content and the interviews will be discussed.

\section{Background}

In order to provide a better understanding of the Chinese SL residents, we first need to understand the distinctive English education background they are from. In China, English is a very important subject for all students. It is the required 
foreign language in Chinese education system. All students from junior middle school (grade 7) to college are required to take compulsory English courses and pass certain exams in order to get their diplomas. English is one of the three core exams that high school students have to take in the College Entrance Examination, with the other two being Chinese and mathematics. It is also required that all college students must pass the National Band Four English Exam prior to their graduation.

Other than these required courses and exams, Chinese students of varied age are also taking extracurricular English classes and activities, English proficiency exams, or study abroad programs. If college graduates can pass the National Band Six English Exam or score really high in other exams such as TOEFL (Test of English as a Foreign Language-ETS, US), IELTS (International English Language Testing System-British Council), BEC (Business English CertificatesThe University of Cambridge, UK), or PETS (Public English Test System-The Ministry of Education, China), they surely will have an advantage in job-hunting with these as proofs of their English proficiency, and most of the potential employers require one or more English proficiency certificates in their job requirements. For those who want to study abroad, TOEFL (Test of English as a Foreign Language), GRE (Graduate Record Examinations), or IELTS (International English Language Testing System), are the exams they must take to provide records of English language ability to overseas institutes.

Nevertheless, English learners in China do not have many opportunities to practice their English in real life because of the scarcity of native or proficient English speakers (Gao, 2006). Therefore, their efforts are put into written exams rather than communication skills due to the pressure of getting different levels and kinds of English proficiency tests. Although there are oral English tests in some of the standardized exams, they only prepare for the oral questions that they are likely to encounter, and they do not do this through interactive practice but through literal recitations of answers they write down. Therefore, even with all the classes and exams they take; many English learners still are weak in using English in real communication settings. Listening comprehension and speaking are the most difficult issues in English learning for Chinese ESL students. They can score very high in exams especially in the reading sections, but they can barely open their mouth to speak when facing another English speaker.

In order to cope with this situation, Chinese English learners who are passionate about learning English creatively organize "English corners" (Li, 2004) to practice their English with other English learners or native speakers as volunteers. They set a certain time and place to meet regularly, usually an evening on one of the weekdays and on a university campus, a park, or some other public space, but this kind of practice requires both space and sufficient and stable number of English speakers to be initiated and maintained, which is quite difficult in places where there are limited number of vigorous English learners on advanced level or limited native speakers who would volunteer to be practiced on.

With the development and popularization of internet in China since the 1990s, English learners also have started using internet as their tool to obtain learning materials, find information about English speaking countries, and interact with other English learners or native English speakers from all over the world. They go into chat-rooms of English websites such as Yahoo! or MSN, set up online Bulletin Board Service (BBS), create websites, and form their own English learning clubs that meet regularly online or offline or both. This kind of English clubs is not only a learning site, but also help to satisfy the learners' "inner needs for social exchange and self-assertion in English (Gao, 2006).” This provides them a strong sense of community among themselves to support both collaborative and autonomous learning in their shared pursuit of language proficiency (Liu \& Littlewood, 1997). As Tomlinson (2005) pointed out that the basic principles of successful language acquisition vary from culture to culture, we should probe into these learners who are in their own country that is different from those who study abroad or those who have native English speakers in their real life to practice with. The internet and forthcoming virtual worlds such as Second Life provides Chinese ESL learners a whole new modality to practice and improve their English with a focus on communication abilities.

\section{The Analysis of the BBS}

Second Life residents in China have formed their own BBS, and the "Chinese Second Life League" is one of the most popular BBS that's shared by Chinese residents. Although it was launched mainly for Second Life information exchange and community communication among Chinese SL residents, a great portion of the discussion content is actually related to English such as translation, proficiency improvement, or communications skills that they may use or need in SL. By the time this study was conducted, there are 17747 registered users of this BBS. Figure 1 is a screen capture of the BBS.

There are altogether four sections in the BBS: Messages from the Board Masters, China SL League Section, Business Section, and Board Management Section. Most of the participants in this BBS are involved in the second and the major section, China SL League Section. In this section, there are 12 forums. Each of the forums has its own theme. One of them is named as "Learning English". Although this is the only one that has English in its name, almost all the other forums have information and discussion concerning English

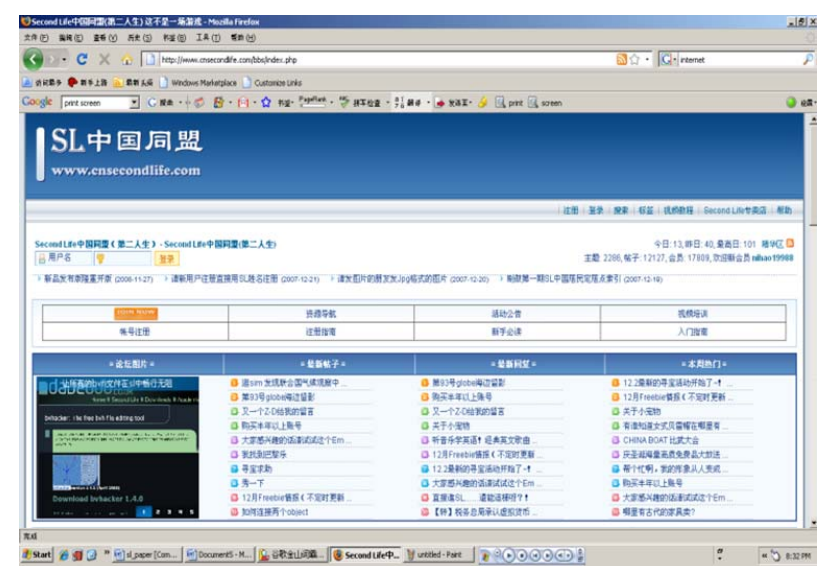

Figure 1.

"Chinese Second Life League" BBS www.CNSecondlife.com. 
in their content. In order to find out how Chinese SL residents perceive their own experience in learning and using English in SL, my analysis begins with this "Learning English" and will later be extended to other forums.

By the time this analysis was conducted, this "Learning English" forum has 64 discussion threads. This might seem to be a very insignificant number to those who are familiar with BBS forums, but this forum actually ranks the sixth in the 12 forums in this BBS on the total number of discussion threads, which means this is a quite popular forum to visit by the users of the BBS. And this popularity is also echoed by the English contents in other forums.

In this "Learning English" forum, most of the threads are on English, especially English instructions on how to explore in SL. The most popular threads are the translated Knowledge Base published by Linden Lab, which is a document for novice users to learn to use and explore SL. It should be noticed that these translated versions were not official translation provided by Linden Lab. They are translated by the SL residents themselves to support and help other residents. However, these translations are not only shared by the users but also critiqued and commented on.

The translator's user ID is "evanc” and s/he provided altogether three volumes of translated Knowledge Base. One of the users commented in Chinese that can be translated in to English as this "This provides the most fundamental and accurate information that I have ever encountered. All beginners in SL should read it. We should thank "evanc" for the hard work." And many others dittoed this by complimenting "evanc" for doing "good" for the community. Many were also very glad to have this as their English is not good enough to comprehend the support information provided by Linden Lab on the official website. They said that this is "evanc"s contribution to the whole community. Many of them said that they would "study" this really hard and they can "learn" a lot from reading the translation. It is very clear that these users have previously tried reading the English version but found it very difficult to comprehend, but with the help of these translations, they can then have reference in Chinese, which will eventually lead to their better understanding of the original English version and better and less frustrating task-performing in exploring in SL. However, people might question the helpfulness of translations in English learning. It is true that in real life it is not always recommended to use translations to learn foreign languages, but in this special context of learning, the virtual world of Second Life, the residents in this world are forced to learn English because the interface and all operations are done in English, which means that even with the Chinese translation they would still need to know the English and use English in their exploration.

Another hot thread is the Chinese localization language package for SL. This package can be installed and then used to localize SL interface into Chinese setting with all the English commands and illustration being displayed in Chinese. This seems to be a very convenient way for the users of this BBS because most of them complained about having to read all the English commands and not having a Chinese version of SL. However, it was surprising to find out that this package was not welcomed as much as one would assume. Many commented on this package after their trials. Here is one representative comment: "The translation is not professional enough to eliminate the communication barriers. On the contrary, it gives me even more troubles in understanding." Many of these users left their suggestions for improvements on specific translation issues they find in the Chinese interface that might result more misunderstandings than eliminating them. The discussion did not cease by then, the user who posted the original package collected all the recommendations for revision, made changes to the package, and posted it again with a note saying that s/he would expect more people to comment and provide suggestions for improvement. The online forum can get SL residents to collaborate on projects like this. It is not just a simple post, any more. It has already served the community as a learning experience for both the person who posted it and those who tried using it. This learning environment and support is not quite possible to be obtained in real life. Therefore, we can say that it is the virtual world and its attractiveness that helped in building the learning community for it. Although, for the residents in SL, they might not get into this world or $\log$ into the BBS with learning English as the sole purpose, they consciously or unconsciously get their English improved. This will also be proven by the results of the avatar interviews in the next section of this paper.

In one of the threads, one user posted a list of English phrases that are commonly used in SL. The title of this thread is "Frequently-used English in SL" (translated from Chinese SL 中常用英语). Here is the content followed by the screen capture of it (Figure 2).

“I'll = ill, OK 简称 $\mathrm{k}$.

Because $=$ coz; Ready $=$ rdy

$\mathrm{A} / \mathrm{S} / \mathrm{L}$ ? 年龄/性别/所在地?

Lol = Laugh Out Loud. 很好笑.

Yup/Nope. 是的/不是的.

newbie $=$ 新手

$\mathrm{c} \mathrm{u}=$ see you.

btw = by the way.

4 = for; $\mathrm{BRB}=$ be right back;

lil = little; $18 \mathrm{r}=$ later $(\mathrm{l}+$ eight $+\mathrm{r})$;

$\mathrm{KIT}=$ keep in touch. ASAP $=$ as soon as possible; talkin' = talking; $r$ = are”.

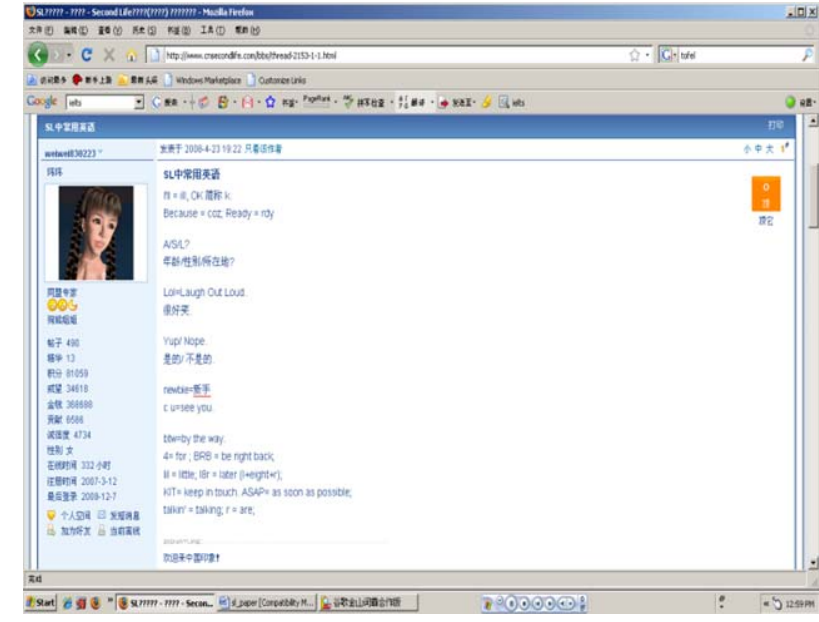

Figure 2.

Sample BBS entry. 
Although this is a really short list of simple English phrases, it received great welcome in the forum. These simple phrases are already used quite naturally by English native speakers in real world, online, and also in SL, but they can be quite difficult for Chinese speaking residents who have no previous exposure to them. One user replied to this thread: "I was so glad that I got this list. Yesterday I used "c u= see you"! If anyone else has more like these, please add them to the list. Thank you very much!” Some other users then added more phrases and abbreviations to the list. Although there are only four replies to this thread, it has been viewed 682 times. This difference in number reveals that many users viewed and probably learned from this list but did not participate in the discussion. This thread is of interest to the users because of its difference from what Chinese English learners have learned before. These kind of not-so-formal chatting English and abbreviations do not appear in English textbooks but are used by native English speakers quite frequently. Although the aim of language teaching is not to teach students informal English, students do get confronted by situations in which they are to respond by using this kind of language. This gap between education and practice is being filled by more and more online study groups as the traditional classroom teaching barely touches on it due to the emphasis on reading and writing in formal contexts. There is also an extreme exam ple of this type of gaps being filled. One of the threads in this "Learning English" forum is "Curse in English." This is the only one that teaches people to curse in English. The user who posted this thread sated that this should only be used in encounters with those English speaker who are not friendly. There is only one reply to this thread. This thread was viewed 385 times but only got one reply. It was not commented by many Chinese because in the essence of Chinese culture, harmony is regarded as very important. Therefore, Chinese people tend not to act drastically when challenged or even mistreated.

They might just choose to leave rather than to fight. However, another reason might be that Chinese residents might not be able to understand some of the insulting language used by unfriendly SL residents from other parts of the world, so they just do not respond to it. However, in English classes, it is never possible that a teacher would teach how to curse in English. Virtual worlds are just like the real world in the sense that you might encounter any type of people. Being equipped with the vocabulary to distinguish friendly or insulting language, in my opinion, is necessary for ESL speakers. As the traditional classroom cannot provide this preparation, the online forums might be a good place to supplement it.

Although these Chinese residents in SL may not speak perfect English and are indeed troubled by the English only version of SL, they did show their interest in learning English and communicate more in SL by using English. This interest not only owes to their personal interests in learning English that derives from different motivations but also represents the need for communication with native English speakers or other English speakers that is impossible in their real life.

This learning experience on the online BBS forums can be classified into group learning. As "the ability for students to feel that they are part of an audience is important to facilitating a sense of shared learning (Ondrejka, 2008: p. 244)," these Chinese residents forms their own groups. Although these groups were not all formed with a purpose to learn English, they do get together and share their experience. Some of the topics they had are about interactions with other SL residents from around the world. For the active participants in the BBS, they have a location in SL that most of them often go to meet their friends or welcome new Chinese residents to the group. This location is named "Chinaboat", and it also became the virtual location where I conducted interviews with some of the residents. The following is a snapshot of the Chinaboat in SL.

The owner of the boat and other residents who often visit this boat are also frequent users of the BBS. They do not only exchange their experience of learning English but also share experience chatting with foreigners they encountered. One interesting post by one of the BBS user is the text of a conversation that he had with an American. The interesting thing about this post is that this is not in English but in Chinese instead. The American SL resident can use good Chinese to communicate with this Chinese resident. Although this conversation took place in this virtual world, the Chinese resident still keeps the typical Chinese students response to a foreigner by saying that "my English is poor" at the beginning of the conversation. It was pointed out by one of the respondents of this post, who is also a friend of the user in SL, that this Chinese resident can speak moderately good English, but his reply was that he did not want to carry on the conversation in English because he did not want to lose "face", not just for himself but for all Chinese in SL. The "face" issue is a very unique phenomenon in Chinese culture. It refers to one's self-esteem. It has always been an issue that is closely related to ESL students in China. They dare not open their mouth to speak English because of the fear of losing one's face. This Chinese resident said that that he insisted on chatting in Chinese because he was afraid that the American resident might look down upon him because of his poor English. This fear of speaking English did not get approved by others who responded to his post, although some of them did express that they did the same thing in SL to avoid speaking English. The person who posted the conversation added at the end of the conversation that he would try to improve his English so that maybe someday he can go ahead and chat with English speakers in English.

Cory Ondrejka (2008) pointed out that one of the uniqueness of SL is that "residents spend a great deal of time in-world educating each other in both direct and indirect ways (p. 240).” This is also true with Chinese residents in SL on learning English with or without intentions. In some of the posts in this BBS, I found that the users expressed that they learned more English than they expected. However, I was surprised to find out that they learn English in various ways other than just chatting with English speakers. The learning happen when they chat to others in Chinese and asking around, when they tried to learn to build something or try to write a script, when they make changes to their avatars, and when they try to read Linden Lab reports or manuals. One user stated that he master more vocabulary in the process of making changes to his avatar than in the English class he took before. Some other users replied to ditto this. They said that when they learned about body parts in English classes, they can only remember the basic vocabulary such as nose, face, eyebrows, etc. However, when they were making changes to their avatars, they grasped more words such as 
hairline, skull, and pupil, words that they have never really talked about in English classes. The increase of vocabulary seems to be universal to the users. Some of them expressed that they were not good students in English classes, but they do learn a lot in SL. This will be further discussed in next section of this paper in which I reported my interviews with some Chinese residents in SL.

From the above analysis of the contents of the BBS, we can easily find out that Chinese residents in SL did use this virtual world as a tool to learn English. They can learn vocabulary, slangs, expressions, and abbreviations that they might not have chance to encounter in their real life due to the scarce native or fluent English speakers whom they can practice on. SL provided a platform for them to improve their English, and they online BBS communication supported this learning experience in the sense of providing group discussion, sharing of resources, and exchange of information.

Then it becomes interesting to me to get to know more about this group of residents in SL. Interacting with them "directly" should make me understand more about their virtual world experience. Therefore, I came up with a simple interview question that I would like them to answer: Did you come into SL with an intention to learn English? This question serves as the opening of conversation between them and me. The following section contains my report on the interviews.

\section{Avatar Interviews}

I conducted interviews on Chinaboat in SL, which is a gathering space for Chinese residents and others who are interested in China or Chinese culture. The interviews themselves only contain one question: How does SL help you to learn English? My intention was that this question can serve well as an opening question to obtain information on the English learning experience of these Chinese residents in SL.

These interviews are avatar interviews, and this means that my avatar interviewed other avatars. Avatars are the virtual figures in SL representing the real people in the real world, and Figure 3 is snapshot of my avatar flying in front of the Chinaboat. Interviewing in SL is different from interviewing in the real world. Although there is voice chat function in SL, I did not use it because I did not want my interviewees feel intimidated by having to talk in their "own" voice. The interviews were done by my avatar to their avatars; therefore,

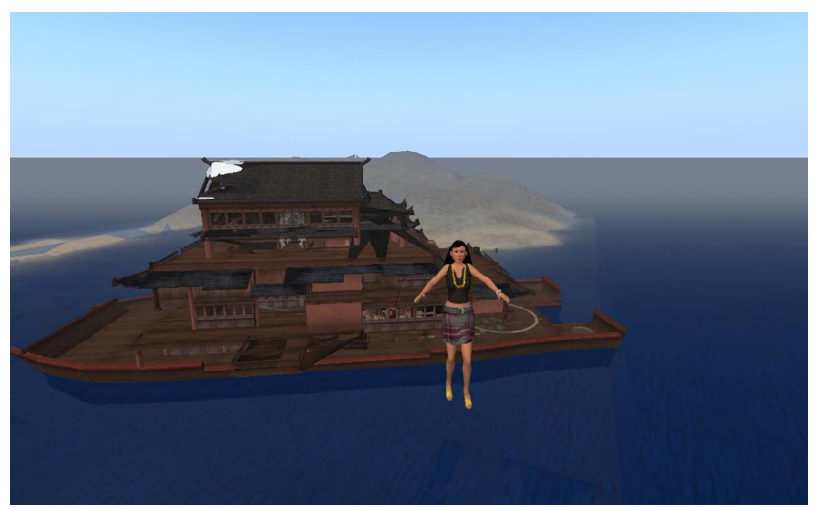

Figure 3.

My Avatar in front of the Chinaboat. there is less to worry about losing one's "face". Figure $\mathbf{4}$ is a snapshot of an interview with a Chinese SL resident that took place on Chinaboat.

The language I chose to conduct the interview in is English. I can use Chinese in SL, but because my target interviewees are those who can speak English, I chose to use English, but very simple English in case they refuse to continue due to the anxiety caused by words they do not know, which indeed happened once during my interview.

I interviewed altogether six residents in SL. From the gender shown by their avatars, there are three female and three male. These interviewees were all found on Chinaboat. All of them are Chinese and in China in the real world. This means that English is their second language and they are not living in a country where English is the native language.

Before I started my interview, I always approach to these people and introduce myself in English first. I first told them my name; then I explained that I was conducting research about SL and would like them answer a simple question. I talked to about 10 residents during my time on Chinaboat, and eight of them agreed to help me with my research. However, two of the eight residents were not Chinese: one Japanese and one Swiss. Six of them completed my interview. Although the other two were not Chinese, I still talked to them and found that it is also worth reporting, which will be included at the end of this section.

Four of the six interviewees told me that they came into SL with an intention to learn English. And two said that they did not think about learning English when they came into SL.

After the simple question which opened our conversation, I would keep chatting with them. One resident whose SL name is "Shuiguai" said that he wanted to learn English and did learn some in SL, but he was still afraid of chatting with other English speakers especially native speakers because they use words that he did not understand. He told me that he need to have his dictionary software open while chatting with native speakers, but sometimes he still could not figure out what they meant. Then he would ask his friends in SL for help on understanding the words or expressions that he was not sure about. Even though he did not have many conversations in English and those he had cannot go deeper than greetings and basic personal information, he still found it helpful in improving his English. He also pointed that the more English conversations he had, the more confidence he had in his own English. During our chat, I found that his English is not poor but indeed not good enough to express

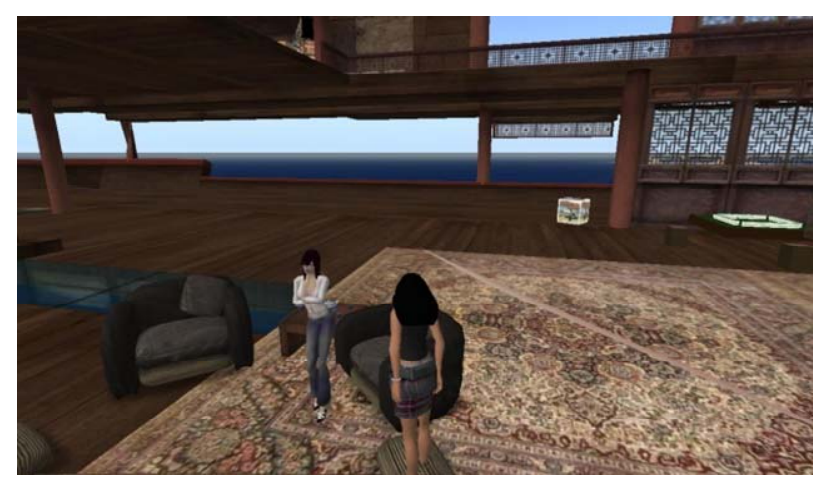

Figure 4.

An interview on Chinaboat. 
himself freely. He was said that he was very happy that he could have a chance to interact with the native English speakers which was almost impossible for him in real life.

From this interview, we can see that SL did provide a platform for people like "Shuiguai" to practice and learn English. We should also notice that group learning also exist in this kind of learning because "Shuiguai" mentioned that he would consult his friends on the difficulties he had. Therefore, group learning here is more self-organized than teacherassigned as in the traditional learning environment. With the "face" issue in Chinese culture being considered, this kind of self-organized learning groups can be more effective than those assigned groups because they have more trust to each other and less concern about being laughed at. "Shuiguai" represents a type of Chinese residents in SL. They came in SL with an intention to learn English but still are afraid to chat while they keep trying. They want to learn and they do learn new words, expressions, and idioms. However, they fear asking questions to those English speakers, especially native speakers, that they are chatting with. They would rather turn to electronic dictionary or their friends for help. This echoes the existence and popularity of the BBS forums. The users of the BBS also go there to obtain information and get answers to their questions. This feeling of belonging to a group makes the learning less intimidating and more comfortable.

Next, I want to talk about one interviewee who said that she did not come in with an intention to improve her English. Her name is "Berry". "Berry" replied firmly that she did not come to learn English because her English is very good. It is true that her English proficiency is the best among the interviewees. However, as our conversation moved on, she said that she did learn some English in SL. She pointed out that she learned English with real native speakers especially Americans. Many Europeans, as "Berry" said, cannot speak good English, and it is very difficult to understand them.

From "Berry"'s experience, I find that even fluent English speakers get their English improved even though they might not do this intentionally. They were able to distinguish native speakers and prefer to communicate with them, while residents like "Shuiguai" did not really have the ability to distinguish or did not have the preference. "Berry" pointed that she learned most when she was "chatting on mic within the US region". She also said that most of the people that she chatted with were friendly and willing to explain if she got confused on the words or expressions they used. Her English is good enough for her to let go the "face" issue, whereas "Shuiguai" did not want to use voice chat because he was afraid of responding slowly and making mistakes.

"Shuiguai" and "Berry" represents the two types of learners. "Shuiguai" came with an intention to learn English, while "Berry" did not; "Shuiguai" dare not use voice chat, while "Berry" prefers voice to typing; "Shuiguai" needs to refer to dictionary or friends to learn new words, while "Berry" was able to learn the meaning of the new words in the context or just by asking the person she was chatting with.

In real world, from my own experience of teaching English to Chinese students, these two types of students are of the most typical ones you can get in a class. However, in the real world, students like "Shuiguai" would only practice with students who are on the similar level with them. They some- times are assigned to practice with students whose speaks better English, but it is very normal to find them keep silent during the discussion or struggled really hard with an attempt to "write" the sentence first in their mind to make sure they do not make stupid mistakes.

Students like "Berry" would always want to express their ideas in front of the class and talk to the teacher whenever possible because their English is so good that they feel they cannot get improved by just practicing with their classmates. These students are also those whom you can find initiating conversations in "English corners", and they always prefer to converse with native speakers who appear in the "English corners".

In the online BBS, there are also "Shuiguai"s and "Berry"s. Users like "Berry" post their successful conversations in the virtual world, and if encouraged by other users or the board managers, they would compose lists of vocabulary, idioms, or abbreviation and post them. "Berry"s also comment or critique on others' post to correct the mistakes or show off their English. While "Shuiguai"s learn from "Berry"s and express their gratitude sincerely or just keep silent because they can easily get daunted by “Berry"s' English proficiency.

Before I move onto the next section of this paper, I would like to also mention my conversations with a Japanese resident and a Swiss resident. Although they did not qualify for my interviews, I found that their experience is also interesting to the subject of ESL. The Japanese resident told me that he came to SL with only one purpose, which is to practice his English. He said that their English teacher, who is an American and obviously a SL fan, teaches in a computer lab where they meet physically and asks them to get into SL to find English speakers to practice. This shows us that SL has been used to teach ESL students in real life. The Swiss resident said that he wanted to practice Chinese in Chinaboat but ended up having to speak English and being practiced on by the Chinese residents. This shows us the willingness of Chinese residents to learn English in SL because of the possibility of speaking to English speakers around the world. Although these two residents are not Chinese, but the Japanese resident's experience reflects the change of ESL education with the change of technology, while the Swiss's shows us the hunger for practice among Chinese English learners.

However, this is a qualitative descriptive study. The results and findings in this paper cannot be generalized to all users in SL who have intention to learning English or other languages, but this should be a good analysis of what and how Chinese SL residents have been utilizing this virtual platform to improve their English or at least attempt to do so.

\section{SL as Educational Tool for Chinese English Learners}

From the above analysis of the present condition of English education in China, the online BBS and the interviews I conducted in SL, we can see that there is a need among ESL learners to practice their English in China, and the current condition cannot fulfill this hunger for English proficiency. Second Life has been new in China, but it has already been used by many as a tool to improve their English proficiency in addition to the education resources available to them in the real world. It is time for us educators and researchers to get into this virtual world to look for possibilities of incorporat- 
ing this new technology into our classes.

Virtual world experience can help our students like "Shuiguai" and "Berry" to achieve their learning outcomes. The analysis of both the BBS and the interviews shows us that learning in virtual world may help to encourage more practice, which is essential to ESL education. No matter the students are novice learners or with good proficiency, they can all benefit from the experience. The group support among their online friends can also serve to help them overcome the "face" issue and get the assistance they need.

We should notice that SL or virtual world is not for all ESL students. They can serve those with at least intermediate English level best because the interface is in English and students need to understand the interface to explore in the world. Those with less English proficiency may find this too difficult to comprehend and operate that this might discourage them from using it as a tool and create even more anxiety.

Although technology has been developed and expanded to education in China, we should understand that the current educational technology in China is still developing. This means that for ESL students in China, it is not easy to get enrolled in a class like the one the Japanese took in Japan that would have a computer lad dedicated to the course. Therefore, issues like the instructors' technical proficiency, hardware availability, and internet bandwidth might slow down the incorporation of virtual worlds into ESL education. With this bear in mind, I would like to offer some suggestions for teachers who would like to pioneer in introducing virtual worlds like SL into their classrooms.

Be supportive. Exploring in virtual world with English as the official language can be threatening to ESL students in China. Therefore, they need both technical support and emotional encouragement. You may also want to refer them to online forums like the BBS analyzed in this paper or create a class group so that they can feel that they are in a group or a community with support and assistance available when needed.

Be open-minded. There are too many possibilities in the virtual world. Students may find their own pace and preference in exploring in the world. Teachers should be openminded enough to let students try exploring by themselves with provided guidelines.

Be patient. It is the same as in the traditional classroom. You may find some students, especially those with better proficiency dive into the virtual world and start practice right away, while those whose English is not so good still keep silent.

\section{Future Research}

James Paul Gee (2003) pointed that computer games have long been ignored in academia except for their potential to teach violence. If today's students have started using more and more technology in their life, we educators should not fall behind.

In this paper, I analyzed the current English education in China in the aspect of lack of practice for students. However, English learners created "English corners" and, with the help of internet, online BBS to communicate and share information with each other. Virtual worlds such as Second Life have already been utilized by ESL learners to meet their needs for practice and hence the improvement of their English proficiency. I suggested that ESL educators and researchers conduct more research and practice on incorporating SL into ESL education in addition to the traditional classroom teaching to provide our student more opportunities to interact with other English speakers that were once impossible.

This study only provides an initial look into this issue. More research is needed to examine the emerging demand on practice among ESL students and possible solutions virtual worlds may offer Future research may be done to further analyzed and classify the SL residents into learning types so that they can be better assisted. Researchers can also look into cultural issues like "face" that's mentioned in this paper to find out their effects in the virtual world. If possible, ESL teachers may start incorporating SL into their class to gather first hand material in studying students' learning experience in relation to technology.

\section{Acknowledgements}

I would like to thank Xi'an International Studies University (10XWA02) and Xi'an Municipal Grant for Social Sciences (12W41) for the grants and support provided for this project.

\section{REFERENCES}

Atkinson, T. (2008). Second Life for educators: Myths and realities. TechTrends, 52, 26-29.

DeWinter, J., \& Vie, S. (2008). Press enter to "say”: Using Second Life to teach critical media literacy. Computers and Composition, 25, 313-322. doi:10.1016/j.compcom.2008.04.003

Diehl, W. C., \& Prins, E. (2008). Unintended outcomes in Second Life: Intercultural literacy and cultural identity in a virtual world. Language and Intercultural Communication, 8, 101-118. doi:10.1080/14708470802139619

Gao, X. (2006). A tale of Blue Rain Café: A study on the online narrative construction about a community of English learners on the Chinese mainland. System, 35, 259-270. doi:10.1016/i.system.2006.12.004

Gee, J. P. (2003). High score education. Wired, 11. URL (last checked 5 December 2008).

http://www.wired.com/wired/archive/11.05/view.html

Jarmon, L., Trahagan, T., \& Mayrath, M. (2008). Understanding project-based learning in Second Life with a pedagogy, training, and assessment trio. Educational Media International, 45, 157-176. doi:10.1080/09523980802283889

$\mathrm{Li}$, Y. (2004). Investigating "English corners" in tertiary campuses: Communication modes and self-identify construction. In Y. Gao (Ed.), Social psychology of English learning by Chinese college students: Motivation and learner's self-identities (pp. 202-226). Beijing: Foreign Language Teaching and Research Press.

Linden Lab (2008). What is Second Life. URL (last checked 5 December 2008). http://secondlife.com/whatis/

Liu, N., \& Littlewood, W. (1997). Why do many students appear reluctant to participate in classroom learning discourse. System, 25, 371384. doi:10.1016/S0346-251X(97)00029-8

Ondrejka, C. (2008). Education unleashed: Participatory culture, education, and innovation in Second Life. In K. Salen (Ed.), The ecology of games: Connecting youth, games, and learning (pp. 229-251). Cambridge: The MIT Press.

Tomlinson, B. (2005). English as a foreign language: Matching procedures to the context of learning. In E. Hinkel (Ed.), Handbook of research in second language teaching and learning (pp. 137-153). Hoboken, NJ: Lawrence Erlbaum. 